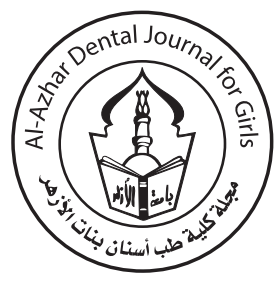

\title{
Treatment of Gingival Recession by Coronally Advanced Flap with Platelet Rich Fibrin (PRF) Versus Chitosan Film
}

\author{
Amal A. Ebrahim ${ }^{1 *}$, Olfat Shaker ${ }^{2}$, Mai S. Attia ${ }^{3}$, Aya M. Abdel Fatah ${ }^{4}$, Eatemad A. Shoreibah
}

Codex : 72/20.10

azhardentj@azhar.edu.eg

http://adjg.journals.ekb.eg

DOI: $10.21608 /$ adjg.2020.13676.1164

Oral Medicine \& Surgical Sciences (Oral Medicine, Oral \& Maxillofacial Surgery, Oral Pathology, Oral Biology)

\section{KEYWORDS}

Gingival Recession, coronally advanced flap,

Platelet Rich Fibrin, chitosan film.

\begin{abstract}
Purpose: The intent of the study was for clinical evaluation of management of solitary and numerous Miller's Class I and Class II gingival recessions by coronally advanced flap combined with PRF or chitosan membrane. Materials and Methods: Randomized study included12 patients with age group ranging between 24-58years with solitary or numerous class I or II gingival recessions in upper and lower anterior teeth. Patients were divided into Group one: managed by coronally advanced flap (CAF) $+(\mathrm{PRF})$.Group two: managed by coronally advanced flap (CAF) + chitosan membrane Clinical attachment loss (CAL), Recession height $(\mathrm{RH})$ and Recession width (RW) were measured at baseline and after 3 months then collected data were analysed using SPSS statistical analysis program. Results: There were significant reductions in CAL, RH and RW of Group one and Group two from baseline to 3 months with statistically significant reduction of CAL and RH in Group two (Coronally Advanced Flap (CAF) + chitosan membrane). Conclusion: The use of chitosan membrane is comparable to PRF in management of Miller's class I or II gingival recessions except for CAL and RH which were more favorable in Group two (Coronally Advanced Flap (CAF) + chitosan membrane).
\end{abstract}

- A paper extracted from Doctor Thesis titled "VEGF levels in the treatment of gingival recession : A comparative study of platelet rich fibrin (PRF) versus chitosan membrane"

1. Associate Lecturer of Oral Medicine, Periodontology, Oral diagnosis and Radiology Department. Faculty of Dental Medicine for Girls. Al-Azhar University, Cairo, Egypt

2. Professor of Bio-Chemistry. Faculty of Medicine. Cairo University, Cairo, Egypt

3. Associate Professor of Oral Medicine, Periodontology, Oral diagnosis and Radiology, Department. Faculty of Dental Medicine for Girls. Al-Azhar University, Cairo, Egypt

4. Lecturer of Pharmaceutics and industrial pharmacy Faculty of Pharmacy for Girls, Al-Azhar University, , Cairo, Egypt

5. Professor of Oral Medicine, Periodontology, Oral diagnosis and Radiology Department. Faculty of Dental Medicine for Girls. Al-Azhar University, Cairo, Egypt

* Corresponding author email: amalib2011@yahoo.com 


\section{INTRODUCTION}

Basically gingival recession is aesthetic and purposeful issues of the periodontium, however additionally one in every of the foremost complexes concerning the etiology and also the treatment modalities. They're outlined as a disclosure of the root surface of the teeth as a consequence of the apical relocation of the gingival margin on the far side the cemento-enamel junction ${ }^{(1)}$.

It's terribly common: fifty hundredth of subjects within the populations studied has a minimum of one or additional sites of one $\mathrm{ml}$ linear unit of root exposure or more; it affects patients with each smart and poor oral hygiene however with the next prevalence in males and in older ages ${ }^{(2)}$.

Solitary or numerous recessions are sometimes related to the anatomical circumstances of soft tissue (e.g., slim group of keratinized tissue), chronic trauma and areas of biofilm deposition (e.g., incorrectly tailored dental restorations/crowding ${ }^{(3)}$. Additionally to aesthetic concerns, gingival recession may also lead to dentin hypersensitivity, cleanness problems, tooth decay ${ }^{(4)}$.

Completely different treatment modalities are delineated to get root coverage. Between them connective tissue graft (CTG) is surgery that helps the foremost predictable and satisfactory results for root coverage and aesthetics ${ }^{(5)}$. But, the SCTG technique requests a second surgical place for a giver space of graft, which can cause additional distress to the patient ${ }^{(6)}$. Subsequently, biomaterials and different transplants, like autologous plasma ${ }^{(5)}$, enamel matrix derivatives ${ }^{(7)}$, and a cellular dermal matrix $(\mathrm{ADM})$, are planned ${ }^{(8)}$.

The coronally advanced flap (CAF) is lone in every of the effective surgical choices in the dealing with Miller's class I and II gingival recessions ${ }^{(9)}$. Guided tissue regeneration come to be a portion of ordinary invasive periodontal apply. These management techniques use barrier membranes that eliminate quick developing cells (i.e., gingival cells, gin- gival fibroblasts) whereas sanctioning mesenchymal ancestor propagation and variation into osteoblasts, periodontal ligament fibroblasts, and cementoblasts ${ }^{(10)}$. These progenitor cells, assumed the house and adequate time for reestablishing lost attachment nearby teeth ${ }^{(11)}$.

PRF is outlined as an autologous white corpuscle and PRF biomaterial ${ }^{(12)}$. The benefits of PRF practice above the higher noted PRP embrace simple planning and lack of needing medication and bovine coagulase. Gently composed thick protein matrix creates PRF an artful material; thence, it will be cut, adjusted, and stitch up simply ${ }^{(13)}$.

PRF was employed in periodontal procedures, as well as angular shape defects ${ }^{(14)}$, sinus surface augmentation ${ }^{(15)}$ and intrabony deficiencies ${ }^{(16)}$. PRF was additionally used as a film to manage numerous gingival recessions. The normal protein design of PRF appears liable for cathartic great quantities of growth factors (transforming growth factor-b, platelet-derived protein, and tube-shaped structure epithelial tissue growth factor) and alternative matrix glycoproteins ${ }^{(5)}$.

Natural merchandise have served as a significant supply of medicine for hundreds of years, and concerning half the prescription drugs in practice nowadays are derived from natural merchandise ${ }^{(17)}$. Between these resources, chitosan (poly- $\mathrm{N}$-acetyl glucosaminoglycan), could be a by-product of polysaccharide, that is that the second most plentiful normal biopolymer, and that could be a major structural element of the frame of arthropods like shellfishes, the cytomembrane of yeasts, and also the cuticle of flies. Chitosan is gained by M-acetylating polysaccharide, and it's a perishable normal biopolymer that's non-toxic and non-immunogenic ${ }^{(18)}$.

Additionally, chitosan has structural features that create it is potential to possess clinical uses as alveolar bone substitute and a framework for cell attachment. Several researches outlined that chitosan might be a good framework for growth factors ${ }^{(19)}$. Chitosan made in varied shapes as well as 
films ${ }^{(20)}$, sponges ${ }^{(21)}$ and fibers and its resorption level may be organized according the concentration of chitosan ${ }^{(22)}$.

Due to the antecedently mentioned doubtless useful properties of each PRF and chitosan, this work was planned to match the efficaciousness of those management modalities in sites with gingival recession.

\section{PATIENTS AND METHODS}

A randomized study was undergone on twelve patients within the age range 24-58years with solitary or numerous class I or II gingival recessions in upper and lower anterior teeth from those noted the Department of oral medication, periodontology, faculty of Dental Medicine Al- Azhar University seeking periodontal treatment.

The subsequent inclusion measures for involvement within the study were used:

1. Patients with good general health.

2. Probing depth $\leq 3 \mathrm{~mm}$.

3. Tooth life.

4. Gingival thickness of the recession space a minimum of $1 \mathrm{~mm}$.

\section{Exclusion criteria:}

1- Smoking patients

2. Pregnant females.

3. Untreated periodontal disorders.

4. Usage of general antibiotics within the past three months or any medication noted to have an effect on gingival conditions.

5. Infectious diseases like liver disease, TB and HIV.

6. Medications and drug abuse.

7. Disappointment to sign printed consent.

The character of this investigation was explained well, and also the patients signed a consent type. The acceptance of ethical committee of the faculty of Dental Medicine Al- Azhar University was obtained.
Study groups: Sample size twelve patients in line with previous study ${ }^{(23)}$. And also the sample size calculated by study style http://www.biomath.info/ power. The twelve gingival recession sites elect for treatment were indiscriminately allotted by a flip of a coin to receive one in every of the subsequent treatment modalities as follow:

Group 1: Gingival recession treated by coronally advanced flap $(\mathrm{CAF})+(\mathrm{PRF})$ (figure 1).

Group 2: Gingival recession treated by coronally advanced flap $(\mathrm{CAF})+$ Chitosan membrane

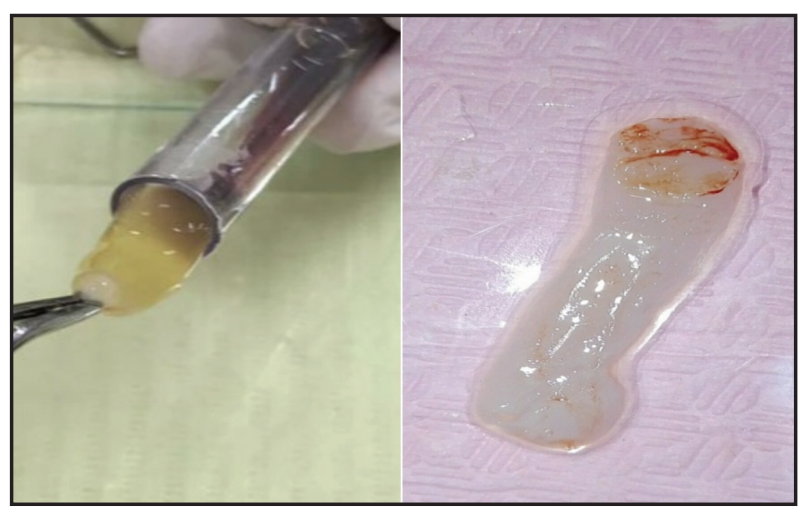

Figure (1) Glass-coated plastic tube after PRF centrifugation and the obtained PRF membrane.

Clinical valuations at baseline, 90 days postoperative was done by a periodontal probe ${ }^{(24)}$.

1. Clinical attachment level (CAL): expanse from $\mathrm{CEJ}$ to the bottom of the periodontal pocket.

2. Recession height (RH): expanse from CEJ to the foremost top purpose of the gingival margin (GM).

3. Recession width (RW): from one margin of the recession to the other margin measured at the CEJ.

Statistical analysis: the various clinical and organic chemistry parameters for all subjects recorded and analyzed by laptop with statistical program SPSS sixteen.(Statistical Package planned for Scientific researches, SPSS, Inc., Chicago, IL, USA) for Windows. 


\section{RESULTS}

Clinical parameters (CAL, RH and RW) were given as mean and variance $(\mathrm{SD})$ values:

1. Changes of means after treatment within every group.

2. Comparison of the share of changes of means that (\%) among two groups.

Changes of mean once treatment at intervals every group from baseline to three months, nearby was a statistically vital modification in means CAL, $\mathrm{RH}$ and RW in each group table (1).

Comparison of the share of Changes of the Mean in Clinical parameters among the 2 groups table (2).
1. CAL: once three months, group I showed the statistically considerably lowest deviation decrease in CAL. group II showed the statistically considerably highest deviation decrease in CAL.

2. RH: once three months, group I showed the statistically considerably lowest deviation decrease in RH. Group II showed the statistically considerably highest deviation decrease in $\mathrm{RH}$.

3. RW: once 3 months, there was no statistically major factor modification of mean RW between 2 groups: each showed the statistically considerably decrease of deviation decrease in RW.

Table (1): Comparison of means and SD for CAL, RH and RW within two groups.

\begin{tabular}{|c|c|c|c|c|c|c|}
\hline \multirow{2}{*}{ Clinical parameters } & \multirow{2}{*}{ Groups } & \multicolumn{2}{|c|}{ Base line } & \multicolumn{2}{|c|}{ 3months } & \multirow{2}{*}{$P$-value } \\
\hline & & Mean & SD & Mean & SD & \\
\hline \multirow{2}{*}{ CAL } & Group I & 4.25 & 1.04 & 3.7 & 0.88 & $0.004 *$ \\
\hline & Group II & 3.5 & 1.14 & 2.5 & 1.14 & $0.001 *$ \\
\hline \multirow{2}{*}{ RH } & Group I & 2.75 & 0.88 & 2.2 & 0.76 & $0.032 *$ \\
\hline & Group II & 1.75 & 0.99 & 1.25 & 0.99 & $0.004 *$ \\
\hline \multirow{2}{*}{ RW } & Group I & 3 & 0.71 & 2.5 & 0.71 & $0.004 *$ \\
\hline & Group II & 2.8 & 0.52 & 2.3 & 0.52 & $0.004 *$ \\
\hline
\end{tabular}

* Significant at $P \leq 0.05$, Changed superscripts in the same row are statistically significantly different.

Table (2): Comparison of means and SD for \% of change of CAL, RH and RW among the two groups.

\begin{tabular}{|c|c|c|c|c|c|}
\hline & \multicolumn{2}{|c|}{ Group one } & \multicolumn{2}{c|}{ Group tow } & \multirow{2}{*}{$P$-value } \\
\cline { 2 - 5 } & Mean \% & SD & Mean \% & SD & \\
\hline $\begin{array}{c}\text { Base line - 3m } \\
\text { CAL }\end{array}$ & $-12.9 \%$ & 10.2 & $-28.6 \%$ & 19.5 & $<0.001 *$ \\
\hline $\begin{array}{c}\text { Base line - 3m } \\
\text { RH }\end{array}$ & $-20 \%$ & 11.8 & $-28.6 \%$ & 15.6 & $0.027 *$ \\
\hline $\begin{array}{c}\text { Base line - 3m } \\
\text { RW }\end{array}$ & $-16.7 \%$ & 4.8 & $-18 \%$ & 5.6 & $0.037^{*}$ \\
\hline
\end{tabular}




\section{DISCUSSION}

The management of gingival recession is changing into a crucial therapeutic issue from the point of view of aesthetics. Aesthetics throughout smiling or perform is changing into the most aim of root coverage techniques ${ }^{(25)}$.

The goals of this work are to reveal 3months effects of the $\mathrm{CAF}+\mathrm{PRF}$ and $\mathrm{CAF}+$ chitosan membrane procedures in root coverage managements. To the most effective of our information, this can be the primary study to match between $\mathrm{CAF}+\mathrm{PRF}$ and $\mathrm{CAF}+$ chitosan membrane.

Smoking could have an effect on the short-run outcome of root coverage procedures and may be rigorously thought-about once designing periodontal cosmetic surgery ${ }^{(26)}$. So, our study enclosed solely nonsmokers. As well, pregnant females were additionally excluded because it was established that current levels of cytokines are stricken by physiological state ${ }^{(27)}$.

PRF could be a second-generation platelet concentrate, and nearby few locations that give information regarding the value of PRF within the management of gingival recessions ${ }^{(5)}$. The author revealed that $\mathrm{CAF}$ operation only or CAF together with PRF is a good practice within the management of numerous gingival recessions ${ }^{(5)}$.

Chitosan was elect within the current study since its each pro-inflammatory and anti-inflammatory effect. It encourages fibroblasts to unleash iterleukin-8 that is concerned in movement and multiplying of fibroblasts and tube-shaped structure epithelial tissue cells ${ }^{(27)}$. It inhibits formation of PGE2 and COX2 induction amid inhibition of TNF- $\alpha$ and IL-1 $\beta$ and development however sweetening of IL10 group ${ }^{(28)}$. IL-10has been reportable to possess a repressive impact on the assembly of pro-inflammatory cytokines and induce the formation of IL-1 receptor antagonist ${ }^{(29)}$.

Researcher ${ }^{(30)}$ reported that chitosan activated the complement system, and C5a was contained within the activated bodily fluid. C5a is documented robust chemoattractant of neutrophils, that is that the 1st line of defense. Comparable results were obtained by researcher ${ }^{(31)}$ who reported that polysaccharide doubtless recovered neutrophils deformability. Studies have additionally shown that chitosan has each antibacterial ${ }^{(32)}$ and anticandidal effects ${ }^{(33)}$.

Once group one and group two were paralleled for CAL, group two showed larger reduction on ninetieth day. It absolutely was statistically vital. These findings correlate with the results reported by researcher ${ }^{(34)}$ the advance of CAL was incontestable by researcher ${ }^{(32)}$ who examined the power of chitosan gel to enhance CAL in chronic periodontal disease. The author terminated that chitosan is bioadhesive and also the decrease in CAL may be permitted by chitosan thanks to this one ancillary and organizing impact on microscopic anatomy design of the gingiva. Furthermore, Researcher ${ }^{(35)}$ found that chitosan inhibited the degradation of animate thing background, stirred the appearance of sort I albuminoid and upregulated alkaline enzyme.

The advance of root coverage that was obtained within the current study could also be explained by researcher ${ }^{(36)}$ who contends that the continual improvement in root coverage could be related to the creeping affection.

\section{CONCLUSION}

The techniques of $(\mathrm{CAF})+(\mathrm{PRF})$ and $(\mathrm{CAF})+$ Chitosan film for managing the gingival recession result in favorable root coverage. Except for CAL and RH which were more favorable in Group II (Coronally Advanced Flap (CAF) + chitosan membrane).

\section{REFERENCES}

1. Shkreta M, Atanasovska-Stojanovska A, Dollaku B, Belazelkoska Z. Exploring the gingival Recession surgical treatment Modalities: A Literature Review. Open Access Maced J MEd Sci. ://doi.org/10.3889/oamjms.2018.185. 
2. Kassab MM, Cohen RE. The etiology and prevalence of gingival recession. J Am Dent Assoc 2003;134:220-5.

3. Heasman PA, Holliday R, Bryant A, Preshaw PM. Proof for the incidence of gingival recession and non-carious cervical lesions as a consequence of traumatic toothbrushing. J Clin Periodontol 2015;42:S237-55.

4. Daprile G, Gatto MR, Checchi L. The evolution of buccal gingival recessions during a student population: a 5-year follow-up. J Periodontol 2007;78:611-4.

5. Aroca S, Keglevich T, Barbieri B, Gera I, Etienne D. Clinical analysis of a changed coronally advanced flap alone or in combination with a platelet-rich fibrin membrane for the treatment of adjacent multiple gingival recessions: a 6-month study. J Periodontol 2009;80:244-52.

6. Roccuzzo M, Bunino M, Needleman I, Sanz M. Periodontal plastic surgery for treatment of localized gingival recessions: a scientific review. J Clin Periodontol 2002; 29:178-94.

7. Zuhr O, Bumer D, Hrzeler M. The addition of soft tissue replacement grafts in plastic periodontal and implant surgery: critical elements in design and execution. J Clin Periodontol 2014;41:S123-42.

8. Aroca S, Keglevich T, Nikolidakis D, Gera I, Nagy K, Azzi $\mathrm{R}$ et al. Treatment of class III multiple gingival recessions: A randomized- trial. J Clin Periodontol 2010;37:88-97.

9. Pini Prato MD, Baldi C, Pagliaro U, Nieri M, saletta D, Rotundo $\mathrm{R}$ et al. Coronally advanced flap procedure for root coverage. Treatment of root surface: Root planing versus polishing. J Periodontol. 1999;70: 1064-76.

10. Nyman S, Gottlow J, Lindhe J, Karring T, Wennstrom J. New attachment formation by radio-controlled tissue regeneration. J periodontal Res. 1987; 22:252-4.

11. Tal H, Pitaru S, Moses O, Kozlovsky A. Collagen gel and membrane in guided tissue regeneration in periodontal fenestration defects in dogs. J Clin Periodontol. 1996;23: $1-6$.

12. Dohan DM, Choukroun J, Diss A, Dohan SL, Dohan AJ, Mouhyij et al. Platelet-rich protein (PRF): A secondgeneration platelet concentrate. part I: Technological concepts and evolution. Oral Surg Oral MEd Oral Pathol Oral Radiol Endod 2006;101:37-44.

13. Toffler M, Toscano N, Holtzclaw D, Del Corso M, Ehrenfest DD. Introducing Choukroun's platelet rich fibrin (PRF) to the the reconstructive surgery. J Implant Adv Clin Dent 2009;1:21-32.
14. Sharma A, Pradeep AR. autologous platelet-rich protein within the treatment of mandibular degree II furcation defects: A randomised trial. J Periodontol 2011:82:1396-403.

15. Mazor Z, piano player RA, Del Corso M, Prasad HS, Rohrer MD, Dohan Ehrenfest DM. Sinus floor augmentation with simultaneous implant placement using Choukroun's platelet-rich fibrin as sole grafting material: A radiologic and histologic study at 6 months. J Periodontol 2009;80:205664.

16. Sharma A, Pradeep AR. Treatment of 3-wall intrabony defects in patients with chronic periodontal disease with autologous platelet-rich fibrin: A randomised controlled trial. J Periodontol 2011: 82:1705-12

17. Clark AM. Natural products as a resource for new drugs. Pharm Res. 13: 1996, 1133-44.

18. Pang EK, Paik JW, Kim SK, Jung UW, Kim CS, Cho KS et al. Effects of chitosan on human periodontal ligament fibroblasts in vitro and on bone formation in rat calvarial defects. J Periodontol. 2005; 76:1526-33.

19. 19. Madihally SV and Matthew HW. Porous chitosan scaffolds for tissue engineering. Biomaterials. 1999;20:1133-42.

20. Zhang H, Sheng ZJ and Hou CL. Effect of chitosan membrane on tendon adhesion and healing. Zhongguo Xiu Fu Chong Jian Wai Ke Za Zhi. 1999; 13: 382-5.

21. 21. Lee YM, Park YJ, Lee SJ, Ku Y, Han SB, Choi SM et al. Tissue engineering bone formation using chitosan/ tricalcium phosphate sponges. J Periodontol. 2000; 71: 410-7.

22. Zhang Y and Zhang M. Calcium phosphate/chitosan composite scaffolds for controlled in vitro antibiotic drug release. J Biomed Mater Res. 62: 2002, 378-86.

23. Eren G, Atilla G. Platelet-rich protein within the treatment of localized gingival recessions: a split-mouth randomised trial. Clin Oral Investig 2014;18:1941-8.

24. De Queiroz Cortes A, Sallum AW, Casati MZ, Nociti FH Jr., Sallum EA. A two-year prospective study of coronally positioned flap with or without acellular dermal matrix graft. J Clin Periodontol 2006; 33: 683-9.

25. Zucchelli G, De Sanctis M. Treatment of multiple recessiontype defects in patients with esthetic demands. J Periodontol 2000;71:150614.

26. Makhseed M, Raghupathy R, Azizieh F, Farhat M. ACirculating cytokines and CD30 in normal human pregnancy and recurrent spontaneous abortions. Oral Diseases. 2006; 12: 112-6. 
27. Mori T, Okumura M, Matsuura M, Ueno k, Tokura S, Okamoto $\mathrm{Y}$ et al. Effect of polysaccharide and its derivatives on the proliferation and protein production of fibroblasts in vitro. Biomaterials 1997;18:947-51.

28. Chou TC, Fu E, Shen EU. Chitosan inhibits prostaglandin E2 formation and cyclooxygenase-2 induction in lipopolysaccharide-treated RAW 264.7 macrophages. Biochem Biophys Res Commun. 2003; 308:403-7.

29. Jenkiins JK, Malyak M and Arend WP. The effect of interleukin 10 on interleukin-1 receptorand interleukin-1 production in human monocytes and neutrophils, macrophages. Biochem Biophys Res Commun 308:403-7. Lymphokine. Cyto kine Res. 1994;13: 47-54.

30. Minami S, Suzuki H, Okamoto Y, Fujinaga T, Shigemasa Y. Chitin and chitosan activate complement via the alternative pathway. Carbohydrates polymers. 1998; 36:151-5.

31. Khanal DR, Okamoto Y, Miyatake K, Shinobu T, Shigemasa Y, Tokura. Phosphated chitin (P-chitin) exerts protective effect by restoring the deformability of polymorphnuclear neutrophil(PMN) cells. Carbohydrates polymer. 2002;48:305-11.
32. Akncbay H, Senel S and Ay ZY. Application of chitosan gel within the treatment of chronic periodontal disease. Journal of medical specialty Materials analysis. Part B, Applied Biomaterials. 2007; 80:290-6.

33. Aksungur P, Sungur A, Unal S, Iskit AB, Squier CA, Senel S. Chitosan delivery systems for the treatment of oral mucositis: In vitro and in vivo studies. J Controlled unleash 2004;98:269-79.

34. Lucchesi JA, Santos VR, Amaral CM, Peruzzo DC, Duarte PM. Coronally positioned flap for treatment of fixed up root surfaces: A 6-month clinical analysis. J Periodontol 2007;78:615-23

35. Zhang Y, Wang Y, Shi B, Xiangrong. A platelet derived growth factor releasing chitosan/ coral composite scaffold for periodontal tissue engineering. Biomaterials2007; 28:1515-22.

36. Papageorgakopoulos G, Greenwell H, Hill Vidal R, Scheetz JP. Root coverage using a cellular dermal matrix and comparing a coronally positioned tunnel to a coronally positioned flap approach. J Periodontol. 2008;79:1022-30. 